\title{
XXIX. On the anatomy of vegetables; intended to substitute many important truths in phytology
}

\section{Mrs. Agnes Ibbetson}

To cite this article: Mrs. Agnes Ibbetson (1816) XXIX. On the anatomy of vegetables; intended to substitute many important truths in phytology , Philosophical Magazine Series 1, 48:220, 96-111, DOI: $10.1080 / 14786441608637622$

To link to this article: http://dx.doi.org/10.1080/14786441608637622

里 Published online: 27 Jul 2009.

Submit your article to this journal $\lceil\pi$

Џ Article views: 2

Q View related articles $\square$ 
The carriage with the short perch was loaded with $6: 0$ That with the long perch with $\ldots \ldots \ldots$.. 5:0

When put in motion they kept together.

The load in the short perch carriage was placed at

the top. They both kept together.

The springs of both were then prevented from acting.

The short carriage had a load at top of $\ldots \quad \ldots 6: 0$ The long carriage was loaded at bottom with $\ldots 5: 3$

The long carriage rather preceded.

\section{Comparison of Roads.}

Two roads were formed, one of gravel, the other of broken stones; two carriages without springs were connected with the peirameter, one running on gravel, the other on stones; the former having a load of $7 \mathrm{cwt}$. the other of $4 \mathrm{cwt}$.; they kept nearly together.

The same carriages were made to run, one on the broken stones, the other on coarse pavement :

The former had a load of .. $\quad . . \quad \ldots 5$ cwt.

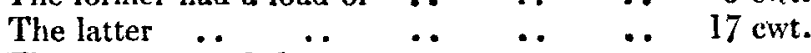

The latter preceded.

In another experiment,

The lst had a load of $\quad \ldots \quad \ldots \quad \ldots$ I cwt.

The $2 \mathrm{~d}$ of $\quad . . \quad \ldots \quad \ldots 10 \mathrm{cwt}$.

They kept together.

Experiments were also tried in order to ascertain the advantage of covering the stones with straw, but little advantage seemed to result.

Your committee cannot close this Report without returning their sincere thanks to Dr. Litton, for the zeal and intelligence with which he attended and reported these experinents; and also their perfect approbation of the unwearied attention and skill with which Mr. William Ergeworth conducted the detail.

R. B. BRYAN.

Thomas Brown.

F. Fox.

XXIX. On the Anatomy of Vegetables; intended to substitute many important Truths in Phytology. By Mrs. Agnes IBBETSON.

To Mr. Tilloch.

$S_{\text {IR, }}-\mathrm{H}_{\mathrm{Aving}}$ now completed the foundation of vegetable life, I shall hope to send you a more regular series of dissections, corrected from many of the errors, doubt and astonishment which 
(often while learning) were too apt to disorder the clearness and conciseness of the picture. So frequently has the whole now been renewed; so continually have 1 gone over the same yearly arrangement, that I can with more perfect perspicuity, and I hope certainty, show the manner in which plants are formed; the mechanism they possess; the impossibility of their being at all sensitive; show the power which food has on plants, the variety of alterations it will produce in their appearance, and how truly each change is adapted to the situation, soil, and aspect for which it was made.

But before I commence this account, I owe to myself and to the public, to show the manner in which my whole studies have been regulated-that they may be proper judges of the credit due to me, whether I deserve the confidence I have ventured to claim, since my offering is, I understand, thought to be a system ; instead of that which it really is, an exact and unaltered daily copy of what Nature truly presents each year in the interior of a plant, and which any person possessing a common microscope may see, provided they will follow the picture as I have done, by a daily review of the increase of the interior of each vegetable, from the first of its commencement to its decay.-In explaining the manner in which I have followed the study for the last sixteen years, I may without exaggeration say, that I believe no one has ever dissected or watched plants with the unwearied diligence and patience that I have; taking up a fresh plant of the same kind every three days for nearly four years following, watching the interior picture, and pursuing each ingredient from its first formation to its perfection, and hence to its destruction. Convinced that a plant was only to be well known by this progressive picture, I (besides all other dissections) submitted to this; and have gained more knowledge, and profited more, by this method, than by any other previously tried. I have been repeatedly told that my dissections are admirable, but that my system is not admissible. I have no system. I think I may venture to say, that any one who should see the natural specimens I could show, would be convinced in a moment, because they explain themselves. How is it possible that the specimens can be true, and yet the facts they elucidate, and bring to light, FALSE? I have with the greatest care avoided forming any system, but that which tine dissections themselves plainly establish. To prove this, I shall bring as an example "the seeds formed in the roots," and mention the different specimens, and give the drawings as they naturally appear in the tree, and as 1 took them, and ask my reader whether any other explanation can be given of such a series of plain facts? In September 1810, laying open the whole root of a beech, and lime, I discovered a quantity Vol. 48. No, 220. August 1816. 


\section{On the Anatomy of Vegetables; intended to sulstantiate}

of powder forming in the extremities of the side-roots. (Plate 1. fig. 1.) Continuing to open a fresh tree as the season advanced, and following up the ingredient in the interior, I saw that powder soon coagulate and form into balls, which, increasing by degrees, moved in a few weeks through the root in every direction, till they all centred in the different vessels of the alburnum (fig. 2), and then mounted in a slow movement, tied together by a slight thread of the line of life. Continuing my examination, I suddenly discovered that the balls had left the alburnum cylinder, and were collected around different buds at the extremity of the last year's shoot (fig. 3). In my next specimens I saw that the balls were entirely left to themselves, while all the buds were in the very act of running up into the new shoot. In the following specimen they were regularly fixed there, the shoot being just formed by the fresh flow of the sap, and completed by this process. The next appearance showed the balls collecting at the bottom of the new shoot, aggregated into the figure of a mulberry (fig. 4). I now redoubled my attention, impatient to see what would follow; when I found that a vessel had been formed (while the balls were collecting), and had dipped into each separate bud $(0,0,0)$. The next process was the running in of the balls into this vessel (see $M M$ ), when so many were egularly dropped into each pericarp, drawn in by degrees by means of the line of life which tied all the balls together (fig. 5). As soon as the balls entered the seed-vessel, a part surrounded them and seemed to fix them in their appropriate places, and the seedvessel closed; but on cutting it open several times within the next fortnight, no further change had taken place; but a very great alteration in the flower, which had gained its calyx and pedrincles. In less than a fortnight more the flower was sufficiently advanced to commence the fructification of the seeds; and the line of life passing through each ball, a figure began to be perceived in the interior (see Lime-seed), which was undoubtedly the embryo of the plant. And the following speeimen showed most plainly, that those very balls, formed at the extremities of the side-roots, running through the middle root to the alburnum, and fixed in the seed-vessel, were really the heart of the seed, since the progressive picture finished by the growth of the $\mathrm{em}$ bryo in the ball.

Is this a system? or, Is it not rather the exact copying of the interior progress of a plant, in which neither the imagination nor even the reason of the dissector has aught to do? I have blindly, I think, followed my copy; my specimens exactly show the different pictures I have explained. How then can they be just, and the explanation false, since they are regularly traced to the fructification of the seed? And how can they be nourishment, 


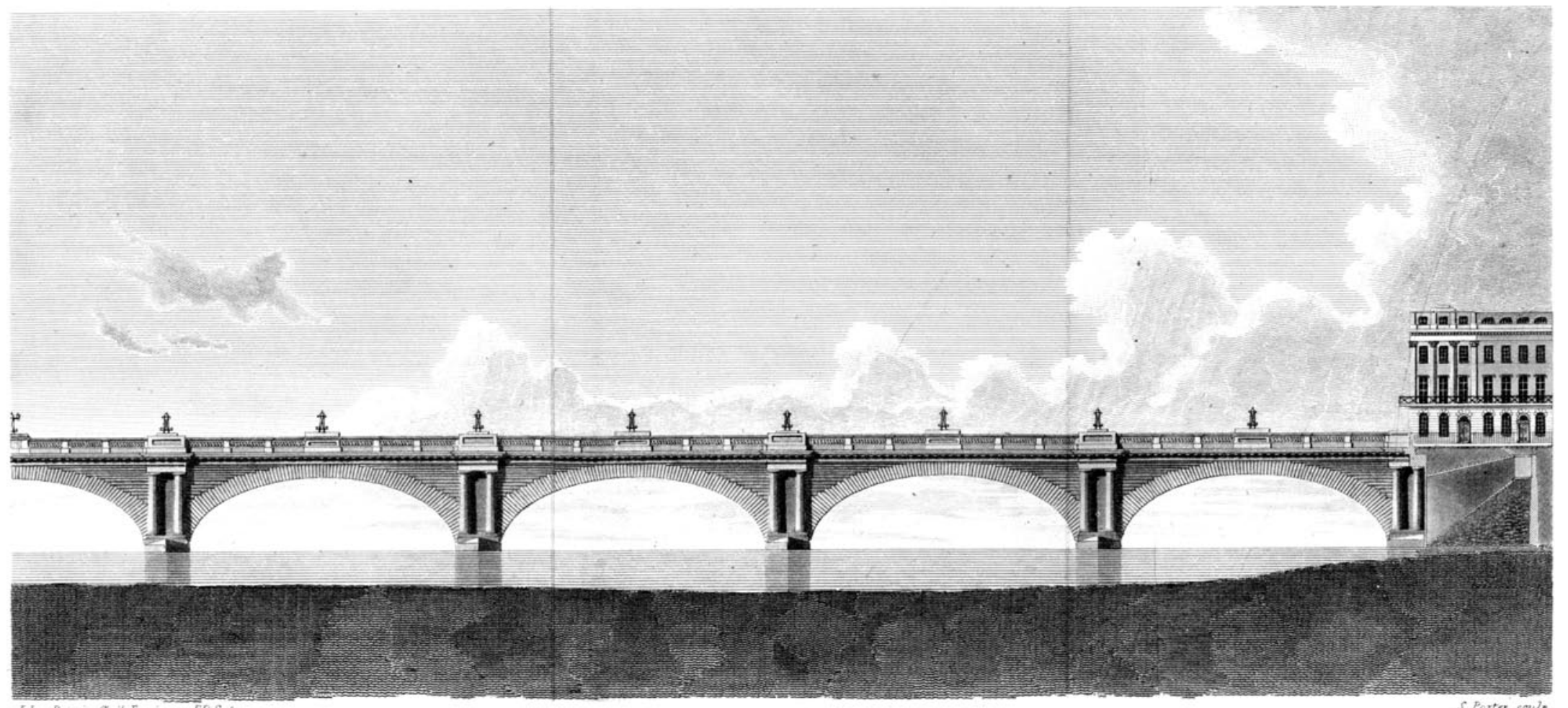

r.

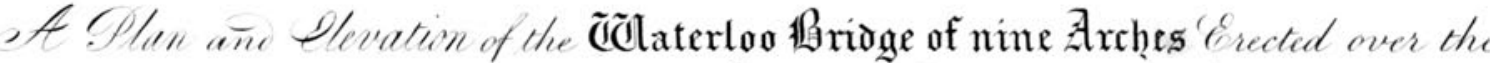
RIVER THAMES near Somerset. Place on the Shand.
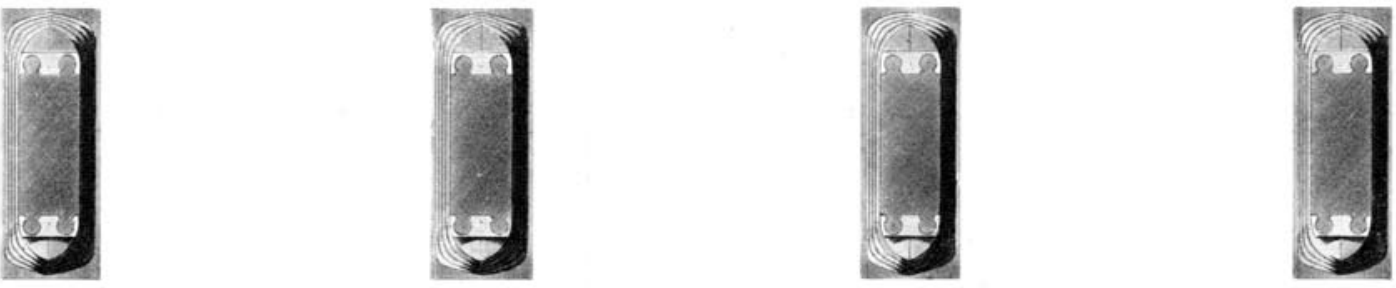

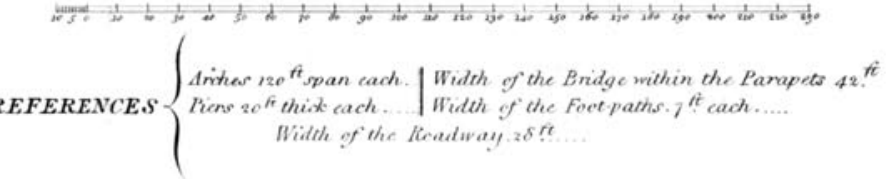

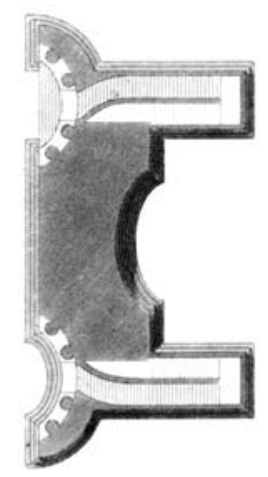


since we follow till the embryo grows within, and till the seed puts on all its outward cover? Between the commencement of this picture and the completion, above twelve specimens are drawn and exhibited, showing them in each different state. How can any one forge all these, and make them exactly agree with the plant? And if they are acknowledged to be true, how can such plain facts be otherwise explained? I have given this example, merely to show the manner in which I study: it is as nearly that adopted in chemistry as possible ; since in botany you follow with your eye the object from state to state while growing, and must therefore perfectly understand the manner of its composition ; while in chemistry the matter is decomposed and recomposed again. Both means can admit of true facts only, and each that I wish to establish will be given with equal clearness and precision. The following propositions I shall first clearly explain, as they are absolutely necessary to the obtaining a thorough knowledge of the forms and nature of vegetable life; and may be called fundamental maxims, which ought first to be proved true, to open the way for more practical laws. These will show what a plant is; and indeed, in describing and drawing up the comparative anatomy of an animal and plant, in this Magazine for August 1815, I exactly fixed those marks of division which this and the next letters will more clearly illustrate.

The chief truths I have hitherto endeavoured to make known are these; the proofs of which I shall enforce with as much expedition as possible.

1. That there is no perspiration in plants.

2. That there is no circulation of sap.

3 . That the spiral wire is the muscle of the plant.

4. That the leaves are the lungs of the plant.

5. That the different divisions of the leaves are formed of the elongations of the bark and inner bark vessels.

6. That the hairs and instruments of that kind are the means which Nature takes to form the different juices according to their various affinities. That these figures were taken for perspiration, but are in reality liquids received from the atmosphere and flowing into the plant, not a juice running from it.

7. That the root is the laboratory of all plants.

8. That the heart of the seeds is formed in the extremities of the side-roots.

9. That the flower is also formed in the middle root, and the pollen in the tap root.

10. That the corolla of a flower is formed by bubbles of water placed in rows, and owes all its beanty, and the lightness of its tint, to the refraction and reflection of the sun on the drops of water which form its pabulum. 
il. That the roots and leaves of a plant will most exactly mark not only what is the soil in which they originally grew, but the situation from which they came, whether a waler plant or a dry plant, a rock or a valley plant, \&c.

12. That the water, and semi-water, and rock plants alone can be said to have direct air-vessels, though I have found them in parasite and early spring plants, such as the crocus and hyacinth.

13. That the leaf owes all its mechanism to the gatherer alone.

When I have shown the absolute truth of all these propositions in a way, I hope, that cannot well be contradicted, I have many more with which constant dissection has acquainted me, which will altogether (I fiatter myself) exhibit a regular system formed by Nature, and established in truth; which may at last force conviction even on those learned botanists, who have such a holy horror of committing thernselves, that they dare not trust their superior minds to hold the scale between truth and falsehood, and try the argument by a fair examination, and by the complete consistency of the opinions.

"My first proposition is, "That there is no perspiration in plants." I have already said much on this subject. I shall now therefore only recapitulate the simple facts, and the manner in which I prove that there is none. I shall first show the difference betweeen perspiration and evaporation, since to comprehend terms clearly, elucidates a sulject beyond any other means. Perspiration is a matter thrown off, in its liquid state, from apertures contrived for the purpose, being a matter injurious to health, and therefore necessary to be repelled : it is often seen in drops of water on the skin. But evaporation is.merely a sign that water exists there. It flies off in vapour unseen; and whether it is or is not condensed again, depends on the presence or absence of one of its constituents, hydrogen, which, the moment it appears, has such an affinity for oxygen that they directly join and recompose water. Now the chief proof which Hales gives of the perspiration of plants is, that if you place a vegetable in a bell-glass, drops of water will soon run down the interior surface. This is true ; but is easily explained., Oxygen flows in quantities from every healthy plant: it is taken from the decomposed water in the vegetable, and the hydrogen is seereted. But when a plant is oppressed and sick, it parts. with this gas; and this is shown by the damp clammy feel it acquires. As soon therefore as confined under a glass without free air, it begins to lose its hydrogen; which immediately fying to the oxygen it had before given out and confined, they again combine and form water. But turn a strong magnifier on the plant while under the glass, and not one drop 
of water will be seen to ooze from the plant, though (if any escaped) the magnifier would make the bubbles as big as overgrown peas. But it escapes in air ; and the joint gases again compose the water, and which runs down the glass.

The philosophers of the last century, not being in the habit of examining plants with the microscope, thought all those figures discovered on the cuticle of the leaves were uncovered bubbles of water, because they appeared clear and pellucid. But all these figures are either cuticles formed by balls standing on high pedestals, or figures of a still more curious make, resembling retorts, cucurbits, and cylinders of various sorts and sizes, divided by regular valves, and formed to produce vacuums, to separate water into its component parts; in short, established for every purpose of chemical affinity; by which means the juices are received from the atmosphere, and changed to the many compounds necessary to compose the various juices of the plant. That balls standing on stalks or long retorts cannot be perspiration, every one will readily own:-but to make the matter plainer still, take two plants of the same sort, expose one to the open atmosphere ; shade the other above. 'The first will be probably covered with dew; the other will remain perfectly $d r y$, not the smallest $d r o p$ appearing on the leaves. Where then is the perspiration? Place this plant in a room, and it will receive dust like any other furniture; nor will that dust agglutinate or thicken : on the contrary, the smallest breath of wind will disperse and blow it all off, leaving the leaves perfectly clear:-a positive proof that no water can ooze from the leaves, or they would exactly resemble the plant when disordered with the honey-dew, and be as nasty in appearance as they then are. And how deformed Nature would be ! for one of its greatest leauties is the vivid green and cleanliness of its shrulis and trees. Would not the dust stick on every part, and spoil all its beauty; or roll off in large balls, smearing the leaf as it passed? It is astonishing that this objection should not occur as so very obvious.

The next proof I shall give of the impossibility of perspiration is, that every vegetable possesses an inpervious skin, through which not a drop of water can pass. To understand and be certain whether plants do or do not possess a skin capable of shutting out all outward moisture, independent of the figures or hairs already mentioned, I procured with great labour near thirty different specimens of this impervious cuticle, in which however I must observe that the pores were most conspicuous. The skins were taken from the outward euticles of leaves, stems, and petals of various plants. Placing them on a glass, with the interior side upwards, I rubbed with the greatest care, with my finger covered with very fine cambric, and soon found that my conG 3 


\section{On the Anatomy of Vegetables; intended to sulstantiate}

jectures svere right; that the mark was only that of the opening pabulum below, impressed by constant motion on the upper cuticle ; since after friction it left behind neither pore nor pattern, but an impervious skin so very fine that not even the solar microscope could display its net-work. Their skins were almost all alike, though some were thicker than others :- some indeed are so very transparent that the liquid appears uncovered, till you touch it, and prove that it is contained in a vessel, which, though so thin, is also so strong as repeatedly to bear detonation. Just the same is the cuticle with which most of the sand plants are covered, which take in so much nutriment. Just the same is the skin which covers most plants, but which is so very transparent, that I am often obliged to place a hair with it in my sliders to mark that there is an object there, - as it is to be seen by the naked eye only when placed in a cross light. With such a skin, then, how can the water pass in and out of the vegetable, but by means of the hairs? And if there was no such cuticle, how would the decomposition of water be effected? since the liquid would leave it at one pore, as fast as it entered at t'ine others:-whereas, secured by this skin, it is to be seen under the cuticle bubbling into air, just as it does when exposed to the Galvanic wire in a glass tube, when water is decomposed. It is by the consistency of my plan that the truth of the whole should be tried. One proposition proves the next-till, copied from Nature, it forms one circle of facts, my mind was wholly incapable of suggesting, except by being led through them by living specimens. Sure no more reasons can be wanting to prove the mistake which philosophers have made in this respect. But there are two or three more as convincing.

The sand plants, the rock plants, take almost all their nutriment from the atmosphere, their roots being incapable of bestowing any, or at most a very trifling quantity. But if they are to lose again in perspiration the greatest part of what they receive, how are they to be nourished? It is the want of the impervious skin in the rock plants, which leaves them open to imbibe all the nutriment they require, being almost without hairs, but receiving the dew, \&c. direct as it falls. But the sand plants, having a quantity of hairs and instruments, have the impervious cuticle, absorbing through these hairs an excessive quantity of nourishment, which thus enters the plant. It was these plants that were said to perspire so much, and it was this liquid collected from the broken instruments that they called perspiration; whereas it is all to be seen entering the plant from every hair, and thus meandering in vessels made for the purpose.

Of what use could perspiration be to plants that have little or 
no heat, no exercise, that deserves the name? What is the use of perspiration to animal life? To free the blood from its redundant water; to expel from the body those particles which from repeated circulation have become acrimonious. But there being no circulation, there is no matter to become hurtful; and as fresh matter is hourly sent into the plant in every way, it cannot want cooling; since the highest heat the plant knows is during fructification, which never exceeds $13^{\circ}$ above atmospheric heat at that time, and can therefore be in no danger from so triffing an increase of temperature. What then is that matter which philosophers collected, and called perspiration? It is a matter which, instead of proceeding from the plant, is wholly drawn in from the atmosphere, and taken from the broken hairs; and which may be regularly traced descending from the points of the hairs, and thus from valve to valve, till it enters the plant. Had simple nutriment alone been necessary, a naked pore would have been sufficient. But to form the juices according to chemical affnity, and specific gravity, wanted more instruments, far more preparation; and this is the reason of the very curious instruments constantly seen on the leaves, and the strange frgures presented to our view: few of the hairs that are not double; few that have not many valves, to alter the juices by degrees as they meet.

I could add many other reasons against this established idea of " the perspiration of plants," did I not fear to tire my reader, and did I not also consider that I have given amply sufficient to convince all those who are not resolved not to be convinced. I am sorry to say, In botany there appears such a holy horror of changing established maxims, that scarcely mathematical evidence against them will suffice. This must at once put an end to every improvement in the science. And yet no one can be more arainst admitting facts without strict evidence than I am. But examination should always be bestowed.

I now turn to mv second maxim, "That there is no circulation in plants." When reading again (and with still stricter attention) the excellent work of Sir J. E. Smith on Botany, (the hest compendium 1 know of what Phytology is at this time) I, to my great surprise, discovered that Mr. Knight considered both bark juice and sap as the same liquid, and forming but one sort. This at once accounts for the strange mistake between $u$, concerning the sap, and its return through the bark. I shall not stop long to consider how he can esteem as the same, two liquids so diametrically opposite in every respect, and which when analysed are so essentially different: the one formed of a sort of gluten and albumen extracted from the earth, and probably proceeding in part from the underground vegetables, of whieh 


\section{On the Anatomy of Vegetables; intended to substantiate}

the earth is full; the other drawing its foundation from the atmosphere, and composed of the narcotic principles, tannin, oils, extractive matter, gums and resins, \&c. \&c. Thus they are as various in their effects as unlike in their appearance; the one tanning leather, the other having no effect of this kind But this confusion has arisen from the firs, where the turpentine is apt to spread not a little into the wood, and thus mix with the sap, which, in this case, loses a little. But its overrunning its proper bounds is no reason for reckoning the two juices the same : the one is compounded in the leaves of the tree, the foundation taken from the atmosphere; the other proceeding from the juices of the earth, and to be considered as the liquid of the ground rather than the juices of the plant.

I shall first show how the bark juice is formed. It is composed in the pabulum of the leaves, to which the juices (taken by means of the hairs from the atmosphere) constantly contribute ; and when the pabulum is completed, the rest of the juices flow in large vessels from the leaf-stem to the bark. Now this is what Mr. Knight calls " the return of the sap." But there is not a drop of sap in it, and his mistake arises from taking the muscles for sap-vessels. However, when once this is proved a mistake, all the fabric must fall with it. That the muscles which run from the wood to the leaves, and which are commonly called the spiral wire, are incapable of carrying sap, is easily shown: two of them are perfectly without aperture; and the middle one, though hollow, contains nothing but oil to humect and lubricate the spiral, that it may not contract, and thus let out. (by continual agitation) the most important part of the plant.

The sap has but two ways of flowing up the tree : the first is up the alburnum vessels, which continue to run up the tree for a whole week or longer, twice in the year, and which is called the barking time, because, in running in its place between the bark and wond, it detaches one from the other, and by separating allows time for the sap to coagulate and form a new row of wood; while the sap also pushing back the bark prepares a fresh row of alburnum, allowing the wood-vessels to lengthen, and by thus increasing runs through the new wond. A large collection of sap is always to be discovered at the bottom of the root at this time, serving as a reservoir for the alburnum; which plainly shows "that this ascension of the sap is managed by a different law than the flow of the sap in the wood," since that has no reservoir below.

The next manner of the flow of the sap is up the wood-vessels. This is a constant rill, which is however much quickened in the morning or evening; but continues more or less throughout the year. 
Sir J. E. Smith is perfectly right in saying that the wood can be divided into such diminutive pieces, it is impossible that they should form sap-vessels. They are not sap vessels, but sap vacancies; which convey the liquid up the tree with more freedom than vessels could, as the escape of the buds horizontally would be apt by moving the vessels to twist them, and thus impede the sap; whereas the vacancies formed in the wood, move to and fro with it, only tied together every inch by a spiral wire which surrounds the top of the aperture (see Plate I. fig. 8), and by contracting and dilating brings them again to their proper places, after they have been disturbed by the passing out of the bud; and as the aperture or passage for the sap is really very large, it will bear a little reducing, without injury to the flow of the liquid. The spiral also prevents their deviating too far from their proper situation. Let a piece of wood be cut quite straight and horizontal, and it will (if much magnified) easily show the spiral vessels passing from one aperture to another (see fig. 8), preventing the wood from warping too much, or obliging it to return to its proper situation.

I shall now show Mr. Knight's opinions (as far as I can understand them), and contrast them with my own. We certainly both agree as to the existing vessels, though differing in the purpose for which they are intended. It is astonishing that, not dissecting progressively, he should so well have ascertained the vessels; this $i$ think wonderful:-but it is only by tracing them daily, from their first exisience, that their purpose can be really proved.

Mr. Knight believes that the sap flows up the spiral vessels in the wood; that they are the sap-vessels, which convey all this liquid up the tree; and that, arrived at the branches, they run up to the bottom of the leaves, and convey the returning sap to the bark downwards. I (on the contrary) am convinced " that the spirals are the muscles of the tree, can convey no sap, that they meander in every part of the leaf to accelerate its motion; and that the large vessels meeting the spirals, at the bottom of the leaf, are the inner bark-vessels running downwards, filling the bark anew which was lost by the late winter, and which is all formed in the leaves.

My first reason against Mr. Knight's opinion is taken from the size of the spirals. That so small a vessel should be chosen for the purpose of nourishing a great tree, when sixty spirals would scarcely make a small thread, seems preposterous. The next reason against it is its extreme twisting and eternal agitation, which in so diminutive a thread must continually impede the progress of the sap. Place a stem of a plant or tree in a cor loured liquor; the spirals run only in the three or four last rows of 


\section{On the Anatomy of Vegetables; intended to substantiate}

the ivood. How comes it then that the whole wood is stained with the liquor, and in the root (where the spirals are stopped) double the quantity of coloured wood is discovered? If the spirals alone received the sap, the wood should be coloured only where they run; it would stop entirely in the root, and only half the wood would be coloured.

I have shown that the sap runs in wood vacancies instead of sap-vessels, and how this reconciles the admirable observation of Sir J.E. Smith concerning the splitting of the wood. Now again, if the spirals carry the sap to the leaves, why put in requisition the largest vessels in the tree to carry the sap on from the leaves downwards to the bark? why such an increase of vessels to convey the same yuantity of liquid?-Surely there is a contradiction here (see fig. 9). But the whole return of the sap may be refuted by the simple truth, that $a$ half pint cannot contain a gallon. Mr.Knight supposes that all the quantity of sap, which in mounting occupies ten times the size of the bark, in descending again runs into the bark-vessels filled already with their own liquid, yet does not increase their size. Thus $a . . . a$ is the bark, and $b \ldots . . . . . b$ the wood. $b b$ is added to $a$, and yet remains the same size ; nor in any degree enlarges, or doubles its number of vessels. Let it descend in cver such small quantities, it must all still pass through the stem of the tree, which is infinitely too narrow in its bark and too small to admit it; besides that it has but its inner bark vessels descending; all the others pass round the tree; nor could I ever discover a vessel in the bark containing sap: and there is certainly no confusing together two liquids differing so much as the bark juice and sap.

That famons trial which is always mentioned so triumphantly as proving the descent of the sap, much better shows the descent of the lark juice. I mean cutting a gash in the tree, and its increasing in the upper and not the lower orifice of the wound. Now if the whole lump formed is cut off and dissected, it is found to be " a collection of coagulated bark juice, which of course conld not proceed downwards; lumps of resin congealed, sap, and half-rotten buds. The sap drawn there hy the lymphatic vessels, on account of the injury done by the cut, and the buds drawn there by the increase of nourishment*'. How, if it had been sap, it could be prevented rumning down, I cannot conceive : but the bark juice coagulates in a moment, and the air wrould soon accelerate this effect. But a more thorough proof may still be given that there is no circulation of sap, by showing that the vessels which Mr. Knight has chosen for the purpose are muscles, and can therefore contain no sap; and that the large vessels are inner bark vessels. Innumerable authors, both

- See Phil. Mag. for Aug. 1815, p. 93.

French 
French and English, are of this opinion, and call them so. But dissecting progressively, it is impossible to mistake the ingredients. From the birth of plants to their end, from the first of their formation to the last, the spirals perform but one part, that of proving the strength of the tree, and its cause of motion.-I now therefore turn to my third proposition.

\section{That the Spiral Wire is the Muscle of the Plant.}

To prove that the spiral wire is the muscle of a plant, and acts on and for the plant exactly as the independent muscle does for the animal body, - I shall first draw up the physical resemblance, showing in how true and perfeet a manner every part suits. In the first place, muscles are to the animal body, the strength of motion. Like the wood of the vegetable, the bone may lay claim to support the figure; but the muscle is the only source of real strength in both. Wherever strength and motion are required, there is the muscle found; and wherever strength and motion are requisite in the plant, there the spiral wire is discovered. As it is involuntary motion only that can be compared to the vegetable, it is that only which I refer to in animals. I showed in my Comparison of animal and vegetable Life*, that the latter had neither brain nor nerves, and could not therefore have any voluntary motion; but that, to make it amends for this apparent privation, it possessed in a very superior degree that involuntary motion to be discovered in animals; that motion which is called the vis insila of the muscles, belongs to no other part; which, when the muscle of an animal is completely divided from every other ingredient, will convulse it and keep it in a continual agitation for a time, especially if the light shines on it. This has been called the vis insita of the muscles. The cause of this vis insita in animal muscles is unknown; but in the spiral wire it is certainly light, and moisture, that act on it; since the moment it is exposed to the light (especially after being detained some time in the dark), its motion is excessive, though perfectly inert before. Nay, $I$ have in my sliders placed an animal muscle in one, and a spiral wire in the other, and they have both on being presented to the light moved much; but the spiral infinitely more than the animal muscle :-still both light and moisture seemed to affect each, though in an unequal degree. Thus the eause of motion, the means of strength, to both muscle and spiral wire, both possessing the same vis insita, who can deny that the spiral is the muscle to the plant? It appears to me to be so positive a proof as to require no other, since the vis insita is the very sign of the muscle. But I shall not trust to that evidence alone, but prove also that it is the source and * See Phil. Mag. Aug. 1815, p. 81. 


\section{$10 \mathrm{O}$ On the Analomy of Vegetalles; intended to sulstantiate}

cause of all strength and of all motion to the plant. View that weak and fragile thing called the corolla of a flower: how beautiful is each petal formed! but so frail, it would seem capable of being destroyed by breathing on it:-and yet it will fold and refold into different forms, when passing from a bud to a fullblown flower; will bear exposure to an evaporating atmosphere, without being hurt; will support the change of weather, rain, and even a storm; and such is its strength, that take the lovely convolvulus tribe, and press the petals with your finger, and you will find a resistance beyond all conception of its force: run a thread through it to prevent its folding; and if your thread is ever so strong, it will either break it, or tear the corolla to pieces; but it will by no means prevent your corolla from closing. Examine what causes this strength; dissect the stripes in which the force is evidently fixed; you will find from four to seven spirals concealed within them. The petal being monopetalous, there are three or four stripes to each apparent division, and it is impossible not to see that the strength resides in them only. What astonishing force to be found in the flower of some salvias! View its high raised banner formed to defend the stamen and pistil from injury; press it with your finger, it is to the stripe alone it owes the preservation of its shape, the force it possesses. This flower has strength enough to oppose a young hornet. I saw the scarlet salvia attacked by one; it had entered the flower, and was attempting to reach the secret nectary below; but it was very near paying with life for its temerity; for, having inserted its head and shoulders within the inward bend of the petals, they were visibly contracting, and began to close above, and in a few $\mathrm{mi}$ nutes the creature would certainly have been drowned; for the juice within increased each moment, pressed up from the secret nectary below:-it was just dead when $I$ took it out, but soon revived enough to be dangerous. It is certain that many flowers have the power of defending their secret nectary by closing; since during my constant watching of plants I have several times found insects thus confined; the muscle thus contracting from the heat of the insect's body, which has quite caloric sufficient to infuence a spiral wire, though perhaps not our thermometers*. The force of the spiral is not only discovered in the flower, but still more in the leaf, as the whole health of the plant depends on the constant motion of the leaves of the trees, which merits them the name of lungs to the plant, though they have few or no air-vessels within them: but the constant motion in which

* The insects feel cold to as, because they are so infinitely colder than our skin ; and we feel the cold, because we part with so much heat to them: but in reality it has more warmth than the vegetable even during tructification-as I shall show in my next letter. 
the spiral wire keeps them, aided by the wind, produces an eternal change in the air around each tree. But for this, the oxygen they give out would remain (owing to its weight) under the plant: but the muscles agitating its multiplied little fans, mix all the different gases together, and keep them when the wind fails in etcrnal agitation. All the mechanism of the leaf is managed not only by the same stripes as the petals, but by the mechanical contrivance of the leaf-stalk. It is the gatherer on each end of the peduncle that is the chief source of motion in the leaves. It is but watching this for a few hours, to see all its different motions, and to be convinced it is to the spiral it owes them, and all its strength also. The stem of the plant possesses not one-tenth part of the motion of the peduncle, nor has it a quarter of its spiral wire, its portion of muscles being exactly equivalent to the action it is obliged to exert. In those leaves that must necessarily turn, follow the motions of the sun, open and close in the morning and evening, there are always more muscles than in the plants that do not open and close. Those plants that do not move their leaves have no spiral wire, such as the firs, lichens, sea weeds, \&c.; but the confervas, that move like a worm and twist in every direction, are, like the tendrils, composed almost wholly of muscles. Take the spirals out of the peduncle; nay, take only a few of them, and the leaf turns no more: take them out of the tendril, and it becomes perfectly inert:- but the spiral you have taken from thence, moves on the glass for hours.

Can more and stronger proofs be given? Those leaves which have most motions have most spiral uire, and have it most twisted; and if the spiral is taken from the plant, it is perfectly inert, while the part taken from it moves eternally. These proofs, added to the vis insita of the spiral, must, I think, be allowed to be as positike evidence as we generally are able to procure of that which is allowed to be true; and therefore sufficient to enable me with confidence to say that the spiral wire is proved to be the muscle of the plant; and that therefore Mr. Knight's idea of the return of the sap inust be a mistake, since the vessels he fixed on for the purpose are incapable of carrying any liquid except a little oil-being the muscles of the plant-and that therefore there is no circulation of the sap; but that the larger vessels are bark-vessels, which can convey no sap, but are full of barkjuice: - that on a thorough examination of the bark, there are but the inner bark-vessels which run down the tree, all the rest moving round it. I hope, therefore, I shall be thought to have proved the three propositions I undertook to show.

In my next I shall show the three following, with the same degree of truth. I should apologize for the style; but it is dif- 
ficult to unite clearness with elegance : to be exactly understood, and to prove the propositions I advance, is all I aine at: to fix the exact foundation of the anatomy of botany, is my only wish: completing this, I think I shall die in peace, and in the hope that I have not lived quite in vain for the science I so highly prize, and to which I have dedicated so many years.

$$
\begin{aligned}
& \text { I am, sir, } \\
& \text { Dawlish, July 2, 1816. }
\end{aligned}
$$

\section{Explanation of the Plate.}

In giving the few specimens, though for want of room I shall not be able to give the twelve; yet I hope I may draw a series sufficient to thoroughly explain the formation of the seed in its regular process. Ist. The view of the radicles and the passage of the powder into ball: the part from $a$ to $b$ being generally lost in the earth when the roo is taken up, if great care is not had to prevent the accident, but they are always to be found in the ground. Fig. 1, natural size, is made rather too large. Fig. 2 is the vessels running through the root, and all centring in the alburnum vessels, and proceeding up to the different buds, but not entering them: The buds are then seen to forsake them, and to pass up into the new shoot just formed, by stalks growing under each bud, as in fig. 7 , and thus running up to their proper places in the new shoot. This is the reason why the new wood is always grooved, even when that shape is lost in more advanced age-the stalks growing within the groove. Fig. 4 is the new shoot round which the buds have arranged themselves, and a vessel formed to convey the balls from bud to bud, dropping so many at each pericarp; which then closes on them, while the collection from which they run at LL decreases hourly till it is all exhausted. In the arum, when the seeds are about to enter the seed-vessel, if a specimen is taken horizontally, the seeds may be seen for the next hour to move into the different pericarps up the stem of the flower at fig. 4, drawn in by the line of life at $d d$. Then follows the last scene, the seeing those very balls fructified, which hat moved from the root upwards, and the embryo growing in the ball. The ball is certainly only the heart of the seed, and reaches from $z$ ta $w$, at fig. 6. I know not how these specimens can be otherwise explained. The fructification proves it the seed; besides that I continue to follow it up till the seed puts on its cover and drops into the earth. And there is no reason brought against these numerous facts, except that it was never discovered before, and that the flower-bud is made (Mr. Knight supposes) in the bark. That the leaf-bud is formed there 1 have always shown; but that 
the flower-bud is formed in the interior is so true, that no peeler or barker but would laugh at us for thinking it doubtful: besides that it has so many different changes, all of which I have exactly traced, that it is impossible 1 strould be deceived : following the interior of a plant evcry three days, and taking up a fresh one for the purpose, I know not how $I$ can miss the trutb in so close an investigation, and that for near four years following.

Fig. 9 disclases the different manner in which the sap-vessels appear when the specimens are cut horizontally, or perpendicularly. The hollow of the vacancies in which the sap runs at $b l i$, fig. $S$, and the manner the spiral is carried round at $d d d$, are most plain, and account for the warping of the wood and its motion back again.

Fig. $Q$ is a specimen of the sumach, showing the bark-vessels at $k k$, and the spirals or muscles at $s s:$ the one to move the leaf, the first to convey the fuice made there to the bark. Surely, when it is recollected what excessive investigation all plants have undergone for the last sixteen ycars, my discovering so much will not be considered as a proof of their falsehood: for, in truth, plants had never before been dissected; for what is cutting a plant two or three times in a year, when compared with following its interior formation day by day? And if you are to know how a watch is made, how can it be known, but by examining and studying all its parts and taking to pieces all its wheels? And here is a more difficult formation; for it is not only a piece of mechanism, but one that alters its appearance though by slow degrees. Yet I again say, no one will or can know or understand a process, but by daily following each ingredient, and not allowing a single week to intervene without the examination of the interior increase of the vegetable he is studying.

[Erkarum.-P. 96, in two instances for substitute r. substantiate.]

$\mathrm{XXX}$. On the Cosmogony of Moses; in Answer to F. E-s. By Dr. Prichard.

To Mr. Tilloch.

SiR, - M $\mathrm{M}$ unwearied adversary F. E-s last letter to have a presentiment that it will call forth a reply, and, like one of the old augurs to whom he bears more than one point of resemblance, has taken care to ensure that his prediction may come to pass. In fact, he has brought a charge a ainst me of having violated the jus belli, the law which custom has imposed on such combatants as him and me. He accuses me not only of taunting him, which was very ill-natured 